\title{
PESQUISA-AÇÃO PARTICIPANTE NO PROCESSO DE EMPOWERMENT DE MULHERES BRASILEIRAS NO CONTEXTO DA MIGRAÇÃO INTERNACIONAL
}

\author{
Participatory Action Research in the Empowering Process of \\ Brazilian Women in the Context of International Migration \\ La Investigación-Acción Participativa en el Proceso de Empowerment de \\ las Mujeres Brasileñas en el Contexto de la Migración Internacional
}

Alcione Leite da Silva ${ }^{1}$

\section{RESUMO}

Este estudo teve por objetivo criar um espaço pessoal e político para o empowerment de um grupo de mulheres brasileiras imigrantes em Melbourne, Austrália, no sentido de refletir sobre suas vidas, as causas e as soluções para seus problemas, e de estimular a ação coletiva e transformativa. Com base na pesquisa-ação participativa, um grupo de 18 mulheres brasileiras elegeu três grandes problemas como foco do ciclo de reflexão-ação: a falta de interação social no seio da comunidade brasileira e de integração na sociedade australiana, a falta de apoio social para enfrentar os problemas de saúde e as barreiras aos cuidados de saúde. Grupos de reflexão constituíram-se em oportunidade para as mulheres planejarem, agirem e avaliarem as suas próprias estratégias de intervenção. Algumas realizações do grupo de mulheres incluíram: o desenvolvimento de seminários e a criação de uma Associação. Neste estudo, a pesquisa-ação participativa foi um processo para acionar o empowerment das participantes, através da filiação em grupo, dos laços comunitários e da ação coletiva.

Palavras-chave: Migração Internacional. Pesquisa Qualitativa. Saúde da Mulher.

\begin{abstract}
This study aimed to create a personal and political space for the empowerment of a group of Brazilian immigrant women living in Melbourne, Australia, to reflect upon their lives, the causes and solutions for their problems, and to estimulate a collective action in changing with quality. Based on a participating action research, a group of 18 Brazilian women elected three major problems as a focus of the cycle of reflection-action: the lack of social interaction within the Brazilian community and integration into Australian society, the lack of social support to cope with health problems, and barriers to healthcare. Group reflections provided an opportunity for women to plan, act and evaluate their own intervention strategies. Some women group's accomplishments included the development of seminars and the creation of an Association. In this study, the participatory action research was a process to trigger participants' empowerment through group affiliation, community bonding, and collective action.
\end{abstract}

Keywords: International Migration. Qualitative Research. Women's Health

\section{Resumen}

Este estudio tuvo como objetivo crear un espacio personal y político para en empowerment de un grupo de mujeres brasileñas inmigrantes en Melbourne, Australia, para reflexionar sobre sus vidas, las causas y soluciones a sus problemas, y para fomentar la acción colectiva y transformativa. Con base en la investigación-acción participativa, un grupo de 18 mujeres brasileñas eligió tres grandes problemas como un enfoque del ciclo de reflexión-acción: la falta de interacción social dentro de la comunidad brasileña y la integración en la sociedad australiana, la falta de apoyo social para se enfrentar problemas de salud y las barreras a la atención de la salud. Grupos de reflexión fueran una oportunidad para las mujeres planificar, actuar y evaluar sus propias estrategias de intervención. Algunos logros del grupo de mujeres incluyeran: el desarrollo de seminarios y la creación de una asociación. En este estudio, la investigación-acción participativa fue un proceso para activar lo empowerment de las participantes, a través de la pertenencia a grupos, vínculos comunitarios y la acción colectiva.

Palabras-claves: Migración Internacional. Investigación Cualitativa. Salud de la Mujer 


\section{INTRODUÇÃO}

Embora várias questões da migração das mulheres estejam bem documentadas na literatura internacional ${ }^{1}$, muito pouca informação existe na área da migração internacional da mulher brasileira. Esse fato merece atenção, considerando os efeitos significativos da imigração sobre a vida das mulheres. Estudos têm documentado o impacto da migração internacional sobre a saúde da mulher ${ }^{1-4}$. A deterioração do estado de saúde da mulher, após a imigração, tem sido relacionada a vários fatores, tais como o período de desenraizamento, as diferenças culturais, a falta de domínio lingüístico, a perda da família alargada e de uma comunidade solidária, a mudança na condição econômica e no status social ${ }^{3,5}$, a discriminação e a intolerância, e os dilemas parentais ${ }^{3}$. A estes fatores somam-se as dificuldades de acesso a cuidados de saúde adequados e a incapacidade para negociar as necessidades de saúde, que podem resultar em atrasos na procura de recursos de saúde ${ }^{1,5}$

Com base na evidência empírica de estudos internacionais, a intersecção entre migração internacional e a vida das mulheres é um fenômeno complexo, multifacetado e dinâmico. A complexidade e a especificidade neste domínio requerem 0 desenvolvimento de estudos de diferentes abordagens para compreender melhor o impacto da migração internacional sobre a vida das mulheres brasileiras e abrir espaços para capacitálas a refletir sobre suas próprias necessidades ou problemas e encontrar soluções para eles.

Nesta perspectiva, este estudo é um recorte de um mais abrangente, e teve por objetivo criar um espaço pessoal e político para o empowerment de um grupo de mulheres brasileiras, imigrantes em Melbourne, Austrália, no sentido de refletir sobre as suas vidas, as causas e as soluções para os seus problemas, e estimular a ação coletiva e transformativa. Foi desenvolvido com base na pesquisa-ação participativa (PAP).

\section{EMPOWERMENT E PESQUISA-AČ̃̃O PARTICIPATIVA: QUADRO CONCEPTUAL E METODOLÓGICO}

Empowerment ${ }^{*}$ é um conceito bem conhecido na literatura internacional e nacional, alicerçado nos movimentos de resistência política, tais como o feminismo, o movimento antipobreza, o movimento ecológico, a luta de sindicatos por locais de trabalho mais seguros, o movimento de paz e, mais recentemente, o racismo e o movimento etnocultural. Nos últimos anos, surgiu como estratégia de capacitação popular para abordar as questões sociais. Empowermenté crucial para reduzir as desigualdades e melhorar as oportunidades na saúde, fortalecer a rede de apoio social e desenvolver a capacidade para a definição de problemas e a tomada de decisão, tanto individual como coletiva ${ }^{6,7}$.

Empowermenté definido como a capacidade de analisar as causas da impotência ou falta de poder, reconhecer as forças sistêmicas opressivas e engajar-se em ações políticas e sociais, em âmbito individual e coletivo, para mudar as nossas vidas.
Nesta perspectiva, empowerment não é algo feito "por" ou "para" alguém, mas sim um processo em que as pessoas entram em contato com seu próprio poder 8 . É concebido como um continuum, englobando o empowerment pessoal, o desenvolvimento de pequenos grupos, a organização comunitária, a advocacia de coalisão e a ação política ${ }^{9}$. Neste estudo, o empowerment tem início na sensibilização e envolvimento das mulheres em um exame crítico das suas vidas quotidianas, da vida de suas famílias e da comunidade, das estruturas que as circundam, para compreender as causas subjacentes às formas opressivas de vida e engajar-se em ações coletivas para transformá-las.

Empowerment é um objetivo importante da PAP ${ }^{8}$. A PAP é baseada em uma ampla gama de pressupostos filosóficos e comprometida com diferentes questões políticas ${ }^{10-11}$. Com base no frutífero diálogo na literatura, nos últimos 20 anos, a PAP tem revitalizado a abordagem de pesquisa na comunidade científica internacional. Tem contribuído para a compreensão do desenvolvimento comunitário, das relações e do ambiente de trabalho, do cuidado à saúde, dos estudos educacionais e desenvolvimentais ${ }^{12}$, entre outras questões.

Neste estudo, a PAP é uma abordagem potencial de intervenção para conscientizar e encorajar mulheres brasileiras a participar em ações transformativas. Ao adotar esta abordagem, o meu entendimento da PAP veio, principalmente, da contribuição de um auto ${ }^{13}$. A PAP é definida como uma abordagem filosófica e política que integra investigação, educação e ação, a fim de criar um espaço pessoal e político em ambientes organizacionais ou comunitários para apoiar as pessoas com menos poder para refletir sobre suas vidas, sobre as estruturas, os sistemas e os relacionamentos em que estão inseridas e incentivá-las a melhorar as suas vidas através de ações transformativas. A PAP é baseada em um forte compromisso com a justiça social e uma visão de um mundo melhor ${ }^{14}$. As mulheres ainda são um grupo cujo poder e voz estão diminuídos em nossa sociedade, pelo caráter opressivo da cultura patriarcal dominante. Neste sentido, a PAP é a abordagem de pesquisa mais adequada para o empowerment das mulheres e para apoiá-las a mudar as suas vidas.

\section{METODOLOGIA}

Esta é uma pesquisa-ação participativa, baseada na adaptação de uma proposta ${ }^{15}$, desenvolvida através de um ciclo de reflexão-ação com as participantes acerca de suas necessidades, o desenvolvimento e a implementação de planos de ação, seguidos da intervenção e avaliação das estratégias adotadas.

\section{Participantes do Estudo}

Dezoito mulheres foram recrutadas através da estratégia de bola de neve (snowball) $)^{16}$, iniciando com participantes-chave a partir de múltiplas fontes. 0 contato inicial com as mulheres foi feito pelo telefone, quando as informaç̃̃es gerais sobre 0 estudo foram fornecidas. Após o convite, todas as mulheres

\footnotetext{
* Optei por utilizar o conceito de empowerment (em inglês) por não existir na língua portuguesa um equivalente que traduza a
} complexidade deste termo em inglês. 
contatadas mostraram grande interesse em participar deste estudo.

\section{Coleta de dados}

A coleta de dados foi realizada através de entrevistas individuais e de dez reuniões de grupo, em suas residências. Através das entrevistas foi possível conhecer os contextos de suas vidas e identificar os principais problemas que gostariam de mudar. Após as entrevistas, elas se engajaram, enquanto grupo colaborativo, em um processo de reflexão crítica para explorar sistematicamente a situação de suas vidas que gostariam de mudar, para desenvolver, implementar, avaliar e replanejar as ações propostas. As entrevistas duraram em média 60 minutos, e os grupos de trabalho, cerca de 3,5 a 4 horas. Os conteúdos foram gravados em fitas cassetes, transcritos, analisados e, posteriormente, validados pelas participantes.

\section{Análise dos dados}

A análise dos dados foi baseada em todos os conteúdos gravados durante as entrevistas e as reuniões de grupo, bem como nas notas de campo. Os conteúdos foram transcritos e lidos com a intenção de alcançar uma compreensão do todo. Os dados foram analisados usando um programa de computador para a análise de dados qualitativos - QSR Nvivo. Os conteúdos das análises foram discutidos e validados no grupo de mulheres. Este processo permitiu o surgimento de novas informações relacionadas aos problemas detectados. A validação dos dados foi também realizada por escrito, e foi-lhes enviado o relatório do estudo.

\section{Rigor do Estudo}

A confiança e a credibilidade do presente estudo foram apoiadas através da triangulação de técnicas de coleta de dados e da validação dos dados, da análise e do relatório do estudo por escrito.

\section{Considerações éticas}

0 estudo proposto foi aprovado pela Comissão de Ética de Pesquisa da La Trobe University. A investigação teve início após uma ampla explicação sobre o objetivo, a finalidade e o processo do estudo, e após o consentimento formal por escrito ser obtido. Foram assegurados a confidencialidade das informações, 0 anonimato de suas identidades e o direito de se recusarem a participar ou de se retirarem do estudo quando assim 0 desejassem.

\section{RESULTADOS}

\section{Características sócio-demográficas das participantes}

A idade das 18 mulheres brasileiras variou de 24 a 57 (média de 44), e elas estavam na Austrália por 3 a 33 anos (média de 15 anos). A grande maioria delas veio para a Austrália com seus maridos ( $n=13)$, apenas cinco decidiram migrar por conta própria. 0 motivo para imigrar, para a maior parte delas, foi a procura de uma vida melhor.

No momento da migração, todas as participantes possuíam algum tipo de educação ou de qualificação profissional (seis tinham curso universitário completo, quatro, curso universitário incompleto, e oito tinham formação profissional). No entanto, como muitas outras imigrantes, não foram capazes de exercer a sua profissão no exterior, pois os seus diplomas universitários não haviam sido reconhecidos na Austrália. A falta de fluência na língua e a ausência de experiência de trabalho na Austrália foram fatores que contribuíram para a mudança em seu status profissional.

As participantes classificaram-se como pertencentes a um grupo de classe média no Brasil, assim como na Austrália. A maioria delas $(n=15)$ trabalhava no Brasil antes da sua partida, quatro estudavam e três eram do lar. Com a exceção de uma que veio para a Austrália para trabalhar na Embaixada Brasileira, todos elas ficaram fora do mercado de trabalho por um curto ou longo período, após a chegada na Austrália. No momento do estudo, cinco mulheres estavam sem trabalho formal. Três delas estavam envolvidas em cursos. Depois da migração, algumas mulheres não puderam continuar trabalhando no mesmo campo profissional e, para trabalhar em outro campo, tiveram de se engajar em novos cursos de formação. As atividades profissionais ou ocupacionais foram: serviço comunitário $(n=3)$, limpeza $(n=3)$, consultora de emprego $(n=2)$, enfermeira $(n=1)$, cuidadora de crianças $(n=1)$, recepcionista $(n=1)$, bibliotecária $(n=1)$, agente de viagem $(n=1)$.

\section{Iniciando a jornada}

Após o meu primeiro contacto com as 18 mulheres, iniciei as entrevistas, seguidas das reuniões de grupo. No início de cada grupo de trabalho, a agenda era negociada e o plano de ação, acordado, seguido de reflexões conjuntas sobre um tema específico previamente aprovado. No final da reunião, empreendíamos uma avaliação da reunião, e todas nós tínhamos a oportunidade de falar sobre nossos sentimentos e percepções do processo e dar sugestões para melhorar nossas reuniões e 0 processo como um todo. Ficou claro para todas nós que estávamos engajadas em um processo colaborativo, com a partilha de responsabilidades e competências, e que o meu papel como pesquisadora era o de facilitadora no processo. Em cada grupo de trabalho foi elaborado um relatório sobre todas as atividades desenvolvidas e as decisões tomadas, incluindo os planos e as avaliações, que foi enviado a todos os membros por correio ou e-mail e aprovado na reunião seguinte.

A partir das discussões sobre a dinâmica do grupo de trabalho, surgiram alguns princípios subjacentes para guiar as nossas reuniões, os quais compuseram a "filosofia do grupo": uma abordagem democrática de tomada de decisão; aceitação e respeito pela diversidade e diferença dos membros do grupo; relações "horizontais" em vez de "verticais" entre os membros, no sentido de tomada de decisão e de execução das ações; prevalência de decisão coletiva, em vez de individual; distribuição igualitária de poder e de informações entre os membros; incentivo e promoção do desenvolvimento pessoal e 
coletivo; encorajamento e ênfase na expressão das qualidades pessoais e nas contribuições positivas.

A partir das reflexões sobre os problemas identificados nas entrevistas, as participantes agruparam as suas necessidades em três grandes categorias inter-relacionadas à(s): 1) falta de interação social dentro da própria comunidade e de integração na sociedade australiana em geral; 2) falta de conhecimento e apoio social para lidar com problemas de saúde, tais como depressão, ataque de pânico, asma e câncer, e 3) barreiras aos cuidados de saúde. Estas três categorias foram focadas nos ciclos de reflexão-ação, realizados nas reuniões de grupo.

A falta de interação social dentro da própria comunidade surgiu como um problema freqüentemente mencionado. Esta falta de interação estava estreitamente relacionada com a falta de apoio social entre elas, o que tornou muito difícil a vida das mulheres. 0 número pequeno de membros da comunidade brasileira, a ausência de qualquer tipo de organização e articulação entre os seus membros e a falta de apoio familiar foram apresentados como as principais preocupações na vida da grande maioria das mulheres no estudo.

Basicamente, seria importante para nós estarmos envolvidas e organizarmos um lugar para as mulheres, onde pudessem ir quando mais velhas. Nós sentimos falta disto. Nós não temos esse grupo que possa dizer 'vamos lá, vamos fazer isto'. Isso porque nós somos um número muito pequeno. Talvez porque a nossa experiência seja diferente; talvez porque viemos de diferentes estruturas econômica e social, não pensamos sobre isso. Mas o tempo está chegando e nós vamos ter que fazer alguma coisa sobre o assunto (Amália)

A interação social entre elas era, principalmente, em pequenos grupos na comunidade, o que colocava muito estresse nos relacionamentos. De acordo com muitas participantes, havia muita "fofoca", o que tornava os relacionamentos instáveis e difíceis. Esta questão foi apontada como uma causa importante para algumas delas serem muito seletivas nas suas amizades e no envolvimento com a comunidade brasileira. Neste sentido, muitas das mulheres, neste estudo, referiram não ser fácil encontrar uma amiga fiel. Outro tema debatido foi a sobrecarga de atividades diárias, sem dar tempo para outras atividades, como a socialização.

A nossa comunidade não é unida. Na minha opinião, todo mundo sofre de falta de tempo e a solidariedade é quase inexistente. As pessoas quase não têm tempo para si e é uma verdadeira vergonha. Penso também que por sermos uma comunidade pequena, não temos como selecionar as nossas amizades. Acabamos por nos relacionar apenas superficialmente com quem está aqui (Raquel)

Os sentimentos de solidão e depressão foram vistos como preocupação primordial na vida das mulheres brasileiras. Algumas mulheres referiram, também, como preocupação os casos de ataque de pânico, câncer e asma. Para algumas das mulheres, a solidão e a depressão estavam presentes, mesmo depois de terem vivido muitos anos na Austrália.

Depois de dois anos vivendo aqui, eu sofri ataques de pânico e depressão. Eu não tinha qualquer controle sobre o meu pensamento. Foi um período muito difícil para mim, assim como para a minha família. Eu tinha mil razões para estar feliz, mas eu não estava. Eu era sempre muito triste, e muitas vezes dizia: "Não consigo fazer isso". Acho que você pode morrer de tristeza. Ela fere o seu coração e você se sente sem saída (Silvia)

Depressão. Penso que este é um problema que muitas mulheres brasileiras têm aqui. Estar longe de sua família e seu país pode tornar você depressiva. Ehá muita gente aqui com depressão, um monte de mulheres brasileiras aqui com depressão (Carol)

Esses sentimentos foram evidenciados pelo fato de não estarem realmente integradas na sociedade australiana. Mesmo para algumas das mulheres que estavam trabalhando e possuíam domínio na língua inglesa, o sentimento de nãopertença à sociedade australiana era uma realidade. Tinham pouco contato com os australianos em decorrência das diferenças culturais. De acordo com algumas mulheres, a falta de integração na sociedade australiana era um problema enfrentado não só pelos brasileiros, mas também por muitos outros grupos étnicos. Além disso, muitas mulheres haviam sofrido algum tipo de discriminação contra elas próprias ou membros da família, tornando-se, portanto, desconfiadas em relação ao povo australiano.

Eu tinha um trabalho muito bom no Brasil. Eu ganhava muito dinheiro, muito mais dinheiro que eu estou ganhando aqui. Eu era uma profissional no Brasil e quando cheguei aqui eu tive de ser garçonete. Foi um grande choque. Você tem que se adaptar a isso. Enão é apenas isso, é toda a cultura 
que é diferente, a linguagem é diferente. É um choque. Demora algum tempo até se adaptar a tudo (Maria)

Acho a sociedade australiana demasiada conservadora para o meu gosto, e, de uma maneira geral, há um sentimento na sociedade contra os imigrantes. Isto é o que eu tenho observado, pois o imigrante chega aqui e trabalha muito, especialmente os asiáticos, que chegam muitas vezes como refugiados... Mas a integração não existe. Penso que a integração ideal só acontecerá daqui a três ou quatro gerações (Abril)

Todos as participantes concordaram que as mulheres brasileiras enfrentam barreiras no acesso aos cuidados de saúde australianos. A dificuldade com o idioma foi o grande obstáculo para conseguir 0 acesso eqüitativo aos serviços de saúde. Este obstáculo parecia ser mais forte nos primeiros dias de imigração, quando a incapacidade para falar a língua também provocou 0 isolamento, a falta de acesso à informação sobre os serviços de saúde e a dificuldade de negociar as suas necessidades de saúde. Essa incapacidade de falar inglês tornou-as dependente de seus maridos.

A barreira lingüística é muito frustrante. É muito difícil quando você deseja expressar as suas idéias e não sabe como fazê-lo. Se você não dominar a língua é realmente difícil. Às vezes você entra em desespero porque não sabe o que dizer, como se expressar; você não sabe como dizer a eles o que quer. É muito difícil porque você não fala a língua; você não está só enfrentando problemas de saúde, mas também está enfrentando outros problemas (Vera)

Se você não conhece o seu direito ao cuidado à saúde, isto pode fazer uma grande diferença (Carla)

Houve comparações entre os sistemas de saúde brasileiro e australiano. A este respeito, as mulheres avaliaram positivamente o sistema brasileiro devido ao tempo mais longo de consulta e a melhor qualidade do relacionamento médicopaciente. Para a grande maioria das mulheres neste estudo, a relação médico-paciente no Brasil era mais afetuosa e os médicos demonstravam uma maior preocupação com o estado psicológico/emocional, em comparação com a ênfase em fatores biológicos no sistema de saúde australiano. As mulheres também se queixaram dos atrasos no acesso a especialistas. Devido às razões econômicas, muitas participantes não possuíam seguros de saúde. Esta foi considerada uma barreira ao acesso imediato aos cuidados de saúde secundário e terciário e a cuidados de saúde de melhor qualidade.
Pois bem, eu tinha no Brasil um médico de quem eu gostava muito. Aqui eu não tenho um médico assim. Você sabe, o que é ir ao médico, sentar, conversar, e ir de novo e de novo. Eu não tenho aqui o que tinha no Brasil e eu realmente sinto falta disso (Elisabeth)

Mas, em geral, se você não tiver seguro de saúde, você tem muitas dificuldades em ser admitida em um hospital. Para algumas cirurgias eletivas émuito difícil conseguir uma vaga para internação (Marcia)

Apesar de viverem muitos anos na Austrália, a maioria destas mulheres não tinham sido capazes de superar totalmente o seu sentimento de discriminação e falta de integração na sociedade australiana. 0 sentimento de impotência, evidente na fala das participantes, era agravado pela falta de confiança em mudar a sua situação.

Os grupos de trabalho consistiram-se em oportunidade para elas se reunirem, para analisarem as suas vidas, para enfrentar e partilhar os seus problemas e encontrar, como um grupo, as soluções possíveis. Apesar das diferenças entre elas, no que se referia ao nível de escolaridade e de experiências de vida, este grupo de mulheres compartilharam algumas experiências semelhantes quanto ao impacto do processo de imigração nas suas vidas. Muitos delas haviam abandonado as suas profissões para seguir seus maridos; várias mulheres viviam sob pressão e sentiam-se isoladas e sobrecarregadas com a dupla jornada de trabalho, com a profissão e a família. Todos estes fatores tiveram um impacto sobre a auto-estima delas. Algumas participantes não haviam tido qualquer contato com outras pessoas brasileiras desde que chegaram na Austrália.

\section{Ação coletiva em direção ao empowerment}

Com base nas reflexões sobre os três grandes temas, as questões identificadas pelo grupo foram: Como superar a falta de interação social dentro da nossa própria comunidade e de integração na sociedade australiana? Como promover o apoio social para as mulheres brasileiras e suas famílias para lidarem com seus problemas de saúde? Como fornecer orientação e ajuda para as mulheres brasileiras e suas famílias para ultrapassarem as barreiras aos cuidados de saúde? A partir do ciclo de reflexão-ação, o grupo de mulheres chegou à conclusão de que a solução para os seus problemas passava pela organização das mulheres, das suas famílias e da comunidade brasileira em algum tipo de estrutura formal. Uma possibilidade era a criação de uma associação de mulheres brasileiras que poderia apoiar as mulheres e suas famílias, residentes na Austrália, assim como os recém-chegados no país. Embora houvesse concordância acerca desta possibilidade, algumas mulheres tinham medo de prosseguir nessa meta por causa de experiências anteriores malsucedidas. Por exemplo, há alguns 
anos, a comunidade brasileira em Melbourne ficou desapontada com um clube brasileiro criado para melhorar a vida social dos seus membros. Este clube tinha se dissolvido por causa de muita discórdia entre os membros do seu conselho. Devido a essa experiência, algumas mulheres, neste grupo, não acreditavam que um outro projeto semelhante poderia ser bem sucedido. No entanto, apesar de alguma relutância, o grupo de mulheres decidiu ir em frente e criar uma associação de mulheres. Naquele momento, o maior desafio enfrentado foi o de criar um sentimento de confiança no processo e ajudar as mulheres a confiar em seu poder para desenvolver tal empreendimento.

Para o processo de reflexão sobre os temas que estávamos desenvolvendo nas reuniões de grupo, acrescentamos a discussão sobre a criação da associação. Vários grupos-tarefa foram criados com a finalidade de: discutir o projeto, buscar material em bibliotecas e na Internet, e visitar associações de outros grupos étnicos já existentes.

Durante esse processo, alguns membros do sexo masculino da comunidade brasileira pediram para participar do projeto. Suas principais questões eram: Por que desenvolver uma investigação só com mulheres, se nós, também, temos necessidades de saúde? Por que criar uma associação só de mulheres, e não uma associação para a comunidade brasileira como um todo? Outras mulheres que não haviam participado no estudo até aquele momento também queriam participar do grupo. Essas reivindicações e demandas foram trazidas para o grupo discutir e tomar decisões. 0 grupo ficou dividido entre aquelas que eram a favor de integrá-los e aquelas que eram contra. Depois de uma longa discussão, ficou decidido que a associação devia ser orientada em direção a toda a comunidade. No entanto, o grupo decidiu prosseguir com o processo iniciado e abri-lo à discussão com a comunidade, em geral, numa fase posterior. Essa decisão criou muitos conflitos entre homens e mulheres da comunidade, com diversas discussões em pequenos grupos e trocas de mensagens eletrônicas entre eles e elas, argumentando contra e a favor da inclusão de outros membros da comunidade no grupo de reflexões. A despeito dos conflitos, o grupo de mulheres ficou coeso em relação à decisão tomada.

0 grupo decidiu, então, desenvolver um inquérito com a comunidade brasileira sobre as suas expectativas, necessidades e sugestões para a formação da associação. Um questionário com perguntas abertas foi construído, distribuído e analisado pelo grupo.

Decidimos, também, a realização de três seminários relacionados com a migração, a saúde e a mudança social. Estes seminários foram abertos à comunidade de língua portuguesa. Os temas abordados no seminário foram: "depressão e o seu impacto na vida de imigrantes" (os oradores foram um médico, um psicólogo e uma enfermeira, sendo esta última uma participante do grupo de trabalho); "ações coletivas e mudança social de imigrantes na Austrália (apresentado por um sociólogo australiano, especialista em cultura brasileira); "solidariedade e mudança social no processo de imigração" (apresentado pela pesquisadora). Esses seminários foram realizados na língua portuguesa, e amplamente divulgados, e contaram com a participação de membros das comunidades brasileira e de língua portuguesa em Melbourne. Os seminários originaram uma nova discussão no grupo no que se referia à inclusão das comunidades de língua portuguesa no projeto da associação, o que foi, então, aprovado pelo grupo. Assim, o projeto, que foi originalmente destinado às mulheres, acabou sendo estendido às comunidades brasileira e de língua portuguesa como um todo. Considerei esta uma decisão política importante no transcurso do processo da pesquisa.

Como resultado do processo de reflexão, o projeto da associação, denominada Associação Brasileira para o Desenvolvimento e Integração na Austrália (ABRISA), foi desenvolvido e aprovado. Mais tarde, através do trabalho de pequenos grupos tarefas, o estatuto da associação foi criado. Após a aprovação do respectivo estatuto pelo grupo de mulheres, ele foi divulgado publicamente para as comunidades brasileira e de língua portuguesa, para posterior discussão e aprovação. 0 projeto e o estatuto foram escritos em ambas as línguas inglês e português.

Membros das comunidades brasileira e de língua portuguesa reuniram-se para adequar o estatuto às normas australianas e desenvolver outro subprojeto orientado para as necessidades dos homens. A assembléia geral foi realizada com a finalidade de discutir e aprovar o projeto e o estatuto da ABRISA. A cobertura da mídia, durante esta etapa do estudo, foi um fator importante para aproximar os membros das comunidades brasileira e de língua portuguesa. Vários membros do grupo de mulheres foram entrevistados várias vezes por uma rádio étnica, para introduzir a $A B R I S A$ ao público. A ABRISA é uma organização legal, não-governamental, sem fins lucrativos, com características humanitárias e com autonomia administrativa, financeira e patrimonial. Tem por missão promover o fortalecimento e o desenvolvimento das comunidades brasileira e de língua por tuguesa e garantir a integração sócio-cultural na Austrália. A filosofia proposta pelas mulheres do grupo foi mantida.

A ABRISA inclui cinco subprojetos, que estão ligados aos três temas estratégicos: informaç̧ão, saúde e educação. Quatro projetos estão relacionados com questões das mulheres, homens, idosos, crianças e adolescentes. 0 quinto projeto, Vibra Brasil, é dedicado a eventos sociais e de expressão artística brasileira e das comunidades de língua portuguesa. Outras atividades desenvolvidas pelo grupo foram: o registro de ABRISA no Australian Department of Fair Trading, e a apresentação de três projetos da ABRISA para dois programas do Vitorian Multicultural Comnission: Community Building Program and Community Grants Program. 
0 primeiro Comitê Executivo da ABRISA foi eleito, e hoje a associação possui sede própria, onde novos subprojetos são desenvolvidos através de um processo semelhante à seguida na implementação do grupo de mulheres. A avaliação das mulheres acerca de suas participações, neste estudo, revelou que o processo as ajudou a ganhar controle sobre suas vidas e confiança em suas capacidades para procurar soluções para mudar suas condições de vida. A oportunidade das mulheres trabalharem em um grupo e perseguir suas metas criou um forte vínculo entre elas, na medida em que estavam buscando soluções para suas necessidades. Durante o processo, comemoramos a oportunidade de estarmos juntas e construímos e nutrimos nossos relacionamentos, criando um clima de confiança e de intimidade.

\section{DISCUSSÃO}

Neste estudo, as reflexões de grupo foram realizadas através de várias etapas, tais como a identificação dos principais problemas das mulheres brasileiras e a criação de um espaço pessoal e político para que pudessem refletir sobre as suas vidas, as causas e as soluções para seus problemas, e para estimular a ação coletiva e transformativa. 0 isolamento social, a falta de apoio social para enfrentar seus problemas de saúde e as barreiras ao acesso aos cuidados de saúde emergiram enquanto questões estruturais, multifacetadas e extremamente complexas, que nortearam as reflexões do grupo. Estes problemas identificados refletiram suas experiências de impotência, de falta de poder ${ }^{17}$. Experienciar sentimento de impotência tem sido considerado um fator de grande risco, que aumenta a suscetibilidade para taxas elevadas de morbidade e de mortalidade ${ }^{17}$.

A articulação coletiva entre as participantes consistiu-se em início do processo de empowerment. As participantes compreenderam que a articulação entre elas, através da criação de ABRISA, poderia ser um caminho possível para que desenvolvessem um sentido de comunidade, para aumentar a participação no processo de tomada de decisões e nas ações da comunidade ${ }^{17}$. Em sua concepção, a ABRISA tem sido visualizada como uma instância política e social, orientada para proporcionar informação, educação e saúde. Por meio de subprojetos, abre espaço para a reflexão sobre os problemas da comunidade, visando ações transformativas. Esta associação apoia igualmente recém-chegados de língua portuguesa, numa tentativa de minimizar os distúrbios e o estresse que estão habitualmente presentes no processo de migração. No desenvolvimento deste estudo, trabalhei no sentido de criar mecanismos necessários para assegurar que o grupo pudesse criar as suas próprias instâncias de apoio para continuar com 0 projeto, após o meu retorno ao Brasil.

Como um grupo, estávamos envolvidas em um processo em que o apoio mútuo, a reciprocidade, a intimidade, a compreensão e a solidariedade estavam presentes. Construímos uma equipe. Éramos um grupo heterogêneo, com diversificadas experiências, aptidões, conhecimentos e competências; todas nós, de diferentes formas, demos a nossa contribuição para o processo. A empatia foi um sentimento poderoso entre pesquisadora e participantes, na medida em que compartilhávamos experiências semelhantes, relativas ao processo de migração internacional.

Engajar-se em um processo de PAP também implicou ser crítica de forma construtiva. "Sermos críticas" não significa (simplesmente ou necessariamente) estarmos em "oposição", mas reconhecermos que, a fim de concretizar nossos valores em cada situação prática, temos de estar prontas para aprender com aquelas pessoas cuja perspectiva é diferente da nossa ${ }^{11: 55}$. Porque este estudo foi sensível às necessidades do grupo de mulheres e da comunidade, e comprometido em mudar e melhorar suas vidas, encontrei ressonância dentro e fora do grupo. Este fato mostra que a PAP é um processo através do qual podemos abrir e ampliar os espaços para novas formas de consciência e de ação, no sentido do reconhecimento das diferenças individuais e coletivas, bem como desenvolver formas mais solidárias de viver em uma comunidade e em sociedade em geral.

Neste estudo, a articulação política e social das mulheres brasileiras foi vista como estratégia-chave para atividades de mudança social. Diria que sem o apoio de um grupo, muitas pessoas seriam incapazes de participar de caminhos mais formais de mudança social, e continuariam a ser historicamente marginalizadas e descomprometidas ${ }^{18}$

Empowerment é um processo político que consiste em diferentes e diversificadas estratégias. Durante o processo da pesquisa, as mulheres perceberam que o empowerment necessitava ser construído entre os membros da comunidade brasileira. Neste sentido, o empowerment foi entendido como um processo coletivo. Este estudo criou uma oportunidade para desencadear o empowerment através do estímulo ao sentido de comunidade, aumentando a participação no processo de tomada de decisões e de ações comunitárias ${ }^{17}$ No entanto, é importante destacar que a comunidade é heterogênea e complexa, e considerável tempo e perícia são necessários para desenvolver uma coesão comunitária sobre as questões que exigem a participação e a ação da comunidade ${ }^{19}$.

\section{CONSIDERAÇÕES FINAIS}

Este estudo criou uma oportunidade para iniciar o processo de empowerment das participantes através da filiação em grupo, da criação de laços comunitários e da ação coletiva ${ }^{17}$. Desencadeou o processo de reflexão-ação, a procura de informações acerca dos principais problemas de saúde, a articulação com outras comunidades étnicas e a criação da ABRISA. Podemos dizer que a ABRISA começou a partir de um sonho de um grupo de mulheres brasileiras. Sonho que se tornou o meu sonho, e nós trabalhamos juntas para tornar esse sonho realidade. Agora é uma realidade. 
APAP é um método para incentivar a expressão do potencial criativo e construtivo de grupos e comunidades em direção à ação coletiva e transformativa. Engajar na PAP exige de nós, como pesquisadoras, a rendição de nossa autoridade/poder para trabalhar de forma colaborativa e coletiva. Como facilitadora do processo de investigação, abri um espaço para a reflexão-ação com base nas prioridades, necessidades e expectativas das participantes. Neste sentido, convivi com as limitações das participantes, com as minhas próprias limitações, bem como com aquelas impostas pelo contexto histórico, cultural, econômico e político, em que o estudo teve lugar. Precisei exercitar a minha capacidade para respeitar os diferentes pontos de vista e de lidar com os conflitos entre os membros do grupo e da comunidade. Algumas vezes, o processo revelou caminhos que extrapolaram as minhas expectativas. Para desenvolver a PAP, necessitei estar preparada para

\section{Referências}

1.Kramer EJ, Ivey SL, Ying YW. Immigrant women's health. San Francisco (USA): Jossey-Bass: 1999.

2.0xman-Martinez J, Abdool SN, Loiselle-Leonard M. Immigration, women and health in Canada. Can J Pub Health 2000; 91 (5): 394-97.

3.Silva AL. Living on the margin: experiences of Brazilian immigrant women in Australia. Rev Européenne d'Insertion Sociale 2008; 1(2): 127-51.

4.Guerin PB, Allotey P, Hussein EF, Baho S. Advocacy as a means to an end: assisting refugee women to take control of their reproductive health needs. Womens Health 2006; 43 (4): 7-25.

5.Allotey P. Travelling with excess baggage: health problems of refugee women in western Australia. The Haworth Press 1998; 28(1): 63-81.

6.World Health Organization-WHO. Ottawa charter for health promotion. Geneva (CH); 1986.

7.Carvalho SR. Os múltiplos sentidos da categoria "empowerment" no projeto de promoção da saúde. Cad Saude Publica 2004; 20 (4): 1088-95.

8.Lather PA. Getting smart: feminist research and pedagogy within the postmodern. London(UK): Routledge; 1991.

9.Labonte R. Health promotion and empowerment: reflections of professional practice. Health Educ Q 1994; 21 (2): 253-68.

10.Reason P, Bradbury H. Preface. In: Reason P, Bradbury H, editors. Handbook of action research: participative inquiry and practice. London(UK): Sage Publications; 2001. p.xxiii-xxxi. enfrentar o desconhecido e viver uma aventura enriquecedora. Independentemente dos resultados, há sempre algumas conquistas pessoais e políticas para celebrar. 0 processo de pesquisa pode ser poderoso, no sentido de que jamais serei a mesma após ter vivido essa experiência.

$\mathrm{Na}$ PAP, as participantes têm de estar envolvidas em todo o processo da pesquisa. No entanto, neste estudo, só pude envolver as participantes, como um grupo, na identificação dos seus problemas e na análise dos dados para criar uma solução. Enfrentei o dilema quando não fui capaz de envolver as participantes na interpretação, que se seguiu ao processo da pesquisa. Para minimizar esta lacuna, enviei o relatório do estudo, por escrito, às participantes e apresentei-o e discuti-o em uma reunião de grupo. Estou ciente das limitações deste estudo, de forma que mantive o meu poder e controle sobre a construção do conhecimento.

11.Winter R, Giddings CM. A handbook for action research in health and social care. London (UK): Routledge; 2001.

12.Petras EM, Popora DV. Participatory research: three models and an analysis. Am Soc 1993; 23(1): 107-26.

13.Hall BL. I wish this were a poem of practices of participatory research. In: Reason P, Bradbury $\mathrm{H}$, editors. Handbook of action research: participative inquiry and practice. London (UK): Sage; 2001. p.171-78.

14. Martin M. Issues of power in the participatory research process. In: De Koning K, Martin M, editores. Participatory research in health: issues and experiences. London(UK): Zed Books; 1996. p. 82-93.

15.Street A. Nursing replay: researching nursing culture together. Melbourne (USA): Churchill Livingstone; 1995.

16.Patton M. Qualitative evaluation and research methods. Newbury Park, CA(USA): Sage; 1990.

17.Wallerstein N. Powerlessness, empowerment and health: implications for health promotion programs. Am J Health Prom 1992; 6(3): 197205.

18.Labonte R. Commentary. Community empowerment: reflections on the australian situation. Community Health Stud 1989; 13 (3): 347-49.

19.Lindsey E, Sheilds L, Stajduhar K. Creating effective nursing partnerships: relating community development to participatory action research. J Adv Nurs 1999; 29(5): 1238-45.

\section{Agradecimento}

A autora agradece ao Conselho Nacional de Desenvolvimento Científico e Tecnológico - CNPq, Brasil, pelo apoio financeiro e pela oportunidade de desenvolver este estudo. 